\title{
A salto de mata. Los procedimientos especiales sancionadores y el proceso electoral 2011-2012
}

\section{Marco Antonio Zavala Arredondo*}

\section{Sumario:}

I. Introducción

II. Sede administrativa: los PES en el proceso electoral

III. Sede judicial: los RAP interpuestos contra PES

IV. Conclusiones y propuestas de reforma

V. Bibliografía

* Licenciado en Derecho por la UNAM; actualmente se desempeña como secretario general de acuerdos de la Sala Superior del Tribunal Electoral del Poder Judicial de la Federación. Los comentarios que aquí se expresan son a título personal y no conllevan, desde luego, una posición del Tribunal. 


\section{Introducción}

En su origen, el procedimiento especial sancionador (PES) fue ideado como un instrumento a disposición de la autoridad administrativa para garantizar que el proceso electoral -especialmente durante las campañas electorales - se conduzca dentro de los cauces institucionales, mediante la interrupción y erradicación de conductas que resulten contrarias a las normas constitucionales y legales que regulan el desarrollo de los comicios. Dicho de otra forma, tal cual como fue delineado por la jurisprudencia de la Sala Superior del Tribunal Electoral del Poder Judicial de la Federación (SSTEPJF), el PES tuvo una clara naturaleza preventiva y reparadora. Sin embargo, la reforma electoral de 2007-2008 y la jurisprudencia subsecuente de la SSTEPJF han transformado notablemente a dicha figura. En la actualidad, el PES cumple con finalidades tan variadas como la imposición de sanciones o la garantía del ejercicio del derecho de réplica, ${ }^{1}$ amén de que hay quienes plantean extender aún más los alcances de dicho instrumento. ${ }^{2}$

Por la importancia que ha venido adquiriendo, no es extraño que el PES rápidamente se haya convertido en un tema de estudio en la doctrina. Diversos trabajos han explicado sus orígenes jurisprudenciales, su regulación explícita a partir de la reforma de 2007-2008, así como algunos de los criterios que con posterioridad se han asumido en la sede jurisdiccional. Unos han señalado algunos de los principales problemas de la figura, mientras que otros más han sugerido modificaciones en su regulación constitucional y legal. ${ }^{3}$ Sin embargo, la

1 Para una explicación sobre los orígenes, regulación legislativa y evolución jurisprudencial del PES, $c f r$. Zavala Arredondo, Marco Antonio, "El procedimiento especial sancionador: Balance de su implementación y propuestas para su perfeccionamiento", en Luna Ramos, José Alejandro (coord.), Sistema de justicia electoral mexicano, México, Porrúa, 2011, pp. 373-425.

2 Por ejemplo, Chacón Rojas parece sugerir que, ante "la falta de sanciones creíbles y oportunas", el PES ofrece "las condiciones para aplicar sanciones de manera más oportunamente [sic]", en materia de fiscalización del origen y destino de los recursos de los partidos políticos durante los procesos electorales. Cfr. Chacón Rojas, Oswaldo, Dinero del crimen organizado y fiscalización electoral, México, Fontamara-Comisión de Fiscalización Electoral, 2011, pp. 212-217.

${ }^{3}$ Cfr. Alanís Figueroa, María del Carmen, "La jurisprudencia del TEPJF: fuente formal de la Reforma Electoral 2007-2008”, en Córdova Vianello, Lorenzo y Salazar Ugarte, Pedro (coords.), Estudios sobre la reforma electoral 2007. Hacia un nuevo modelo, México, 
mayoría de estos trabajos suelen realizar análisis estrictamente legales -y en el mejor de los casos, jurisprudenciales- por lo que no contamos con un análisis sobre la forma en que ha operado, en la realidad, tan discutida y polémica figura.

El presente trabajo busca, precisamente, ofrecer un panorama sobre cómo operó, tanto en la sede administrativa como en la jurisdiccional, el PES durante el proceso electoral federal 2011-2012. En última instancia se busca hacer un diagnóstico sobre el funcionamiento del PES, que permita identificar las causas de sus principales deficiencias y, a partir de ello, plantear posibles soluciones.

Para ello, en el siguiente apartado (II) se presenta un panorama cuantitativo sobre las principales tendencias en la recepción y resolución de los PES en la sede administrativa durante el proceso electoral. En el apartado III se pasa a la arena judicial para presentar las estadísticas descriptivas de los recursos de apelación (RAP) interpuestos contra PES relacionados con el mencionado proceso federal. Por último, en el apartado IV se contienen las principales conclusiones de este análisis y se plantean algunas propuestas de reforma encaminadas a mejorar el funcionamiento del PES.

TEPJF, 2008, pp. 3-24; Alcocer, Jorge, "Sin ton ni son", Reforma, 10 de agosto de 2010, p. 10; Aljovín Navarro, Jorge David, Procedimiento especial sancionador: manual en materia electoral, México, Porrúa, 2012; Ballados Villagómez, Patricio, "La visión desde el Tribunal”, Voz y Voto, núm. 219, mayo de 2011, pp. 35 y ss.; Becerra, Ricardo, "Una reforma electoral con precisión (y sin lágrimas)”, El Universal, 20 de noviembre de 2009, p. 22; Becerra, Ricardo, "La visión desde el IFE", Voz y Voto, núm. 219, mayo de 2011, pp. 31 y ss.; Becerra, Ricardo, "Piensen en cargar un elefante (y luego en el IFE)", Nexos, junio de 2011, http://www.nexos.com.mx/?P=leerarticulo\&Article=2099321; Córdova Vianello, Lorenzo, “¿Árbitro electoral o MP?”, El Universal, 22 de abril de 2009, p. 25; Córdova Vianello, Lorenzo, "La reforma electoral de 2007-2008 cuatro años después: apuntes para un balance de su instrumentación”, Revista Mexicana de Derecho Electoral, núm. 1, enero-junio de 2012, pp. 3-27; Elizondo Gasperín, Ma. Macarita, Prontuario electoral. Procedimiento administrativo sancionador, México, Porrúa-UNAM, 2009; Luna Ramos, José Alejandro, "Los conflictos entre partidos políticos durante las campañas electorales: Una propuesta de ampliación a la jurisdicción electoral", Revista de la Facultad de Derecho, México, t. LVII, núm. 247, enero-junio de 2007, pp. 33-62; Orozco Henríquez, José de Jesús, "Medios y elecciones. El reto de la equidad y la libertad de expresión", en Ackerman, John M. (coord.), Elecciones 2012: en busca de equidad y legalidad, México, Instituto Belisario Domínguez del Senado de la República-UNAM, 2011, pp. 289-291; Roldán Xopa, José, El procedimiento especial sancionador en materia electoral, México, IFE, 2012; Salazar Ugarte, Pedro, "Un IFE sin poder para sancionar", El Universal, 16 de marzo de 2010, p. 18; Woldenberg, José, “El IFE como juez”, Reforma, 18 de junio de 2009, p. 12. 


\section{Sede administrativa: los PES en el proceso electoral ${ }^{4}$}

Si se compara el más reciente proceso electoral federal con lo acontecido en el de 2008-2009, lo primero que destaca es un incremento en el número de PES. La gráfica I muestra que, de un proceso electoral a otro, el número total de PES pasó de 1026 a 1350, lo cual representa un incremento del $31.6 \%$. Asimismo, la gráfica permite ver que dicho aumento se presentó en los procedimientos tramitados y resueltos tanto a nivel central como a nivel distrital. ${ }^{5}$ En el primer caso, las denuncias y quejas de PES se incrementaron en $21.8 \%$, mientras en el segundo el aumento fue del $37.0 \%$.

\section{Gráfica I \\ Comparativo PES durante procesos electorales federales}

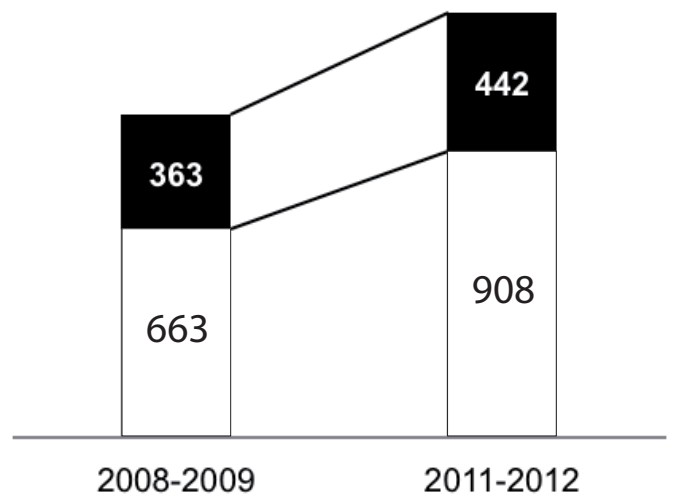

\section{-PES a nivel central $\square$ PES a nivel distrital}

Fuente: elaboración propia con base en datos del IFE.

${ }^{4}$ Los datos que se presentan en este apartado fueron obtenidos del "Informe que presenta el Secretario del Consejo General en cumplimiento al artículo 10 del Reglamento de Quejas y Denuncias del Instituto Federal Electoral" del 23 de agosto de 2012. Por su parte, las referencias estadísticas al proceso electoral federal 2008-2009 se retoman de Zavala Arredondo, Marco Antonio, op. cit.; IFE, Informe general sobre la implementación de la reforma electoral durante el proceso 2008-2009, México, IFE, 2010.

5 Destaca, también, que en ambos procesos electorales prevalecieron los procedimientos distritales sobre los centrales. En 2008-2009 la tasa distrital/central fue de 1.82, mientras que en 2011-2012 fue de 2.05. Lo anterior significa que, grosso modo, por cada PES a nivel central se tramitaron dos a nivel distrital. 
A primera vista, podría pensarse que el aumento en la presentación de quejas y denuncias fue producto de un incremento en el número de (supuestas o alegadas) infracciones a la normatividad electoral. No obstante, para la interpretación del dato debe considerarse lo siguiente. En primer término, en las elecciones intermedias de 2009 sólo se renovó a la Cámara de Diputados, mientras que en las de 2012 se eligieron a diputados, senadores y presidente de la República. En ese sentido, el incremento en la presentación de quejas y denuncias de PES podría deberse, simplemente, al aumento en el número de procesos electorales. ${ }^{6}$

Otra tendencia importante es que, de nueva cuenta, los PES prevalecieron sobre los procedimientos sancionadores ordinarios (PSO). De acuerdo con la información del Instituto Federal Electoral (IFE), en el proceso electoral 2008-2009 por cada PSO se presentaron 2.2 $\mathrm{PES}^{7} \mathrm{Y}$, de hecho, en los más recientes comicios federales la proporción entre uno y otro aumentó notablemente: por cada procedimiento ordinario se presentaron 6.3 especiales. ${ }^{8}$ Contra la noción intuitiva derivada del lenguaje, la estadística revela que los procedimientos especiales son la norma, y los ordinarios, la excepción.

Ahora bien, ¿qué tipo de violaciones se conocieron mediante los PES a nivel central?? La gráfica II muestra que predominaron cua-

${ }^{6}$ De hecho, si consideramos que en el proceso de 2008-2009 se eligieron 500 cargos (300 diputados de mayoría relativa y 200 de representación proporcional) y se tramitaron 1026 PES, tendremos que, en promedio, se presentaron 2.05 procedimientos por elección. En cambio, en el proceso 2011-2012 se eligieron 629 cargos (500 diputaciones, 128 senadurías y la Presidencia) y se tramitaron $1350 \mathrm{PES}$, lo cual da un promedio de 2.15 procedimientos por cargo renovado. Si bien hay un ligero incremento en la tasa (0.10), lo cierto es que ambos datos son similares. Con todo, la experiencia con la que se cuenta hasta el momento es insuficiente como para concluir que se ha estabilizado el número de PES en cada proceso electoral, pues es necesario ver las tendencias que se presenten en procesos electorales posteriores. Además, para poder consolidar una tendencia se requeriría tener información sobre la elección específica sobre la cual guardan relación los PES, con la cual no se cuenta al momento de preparar esta contribución.

7 En efecto, en dicho proceso electoral se presentaron 1026 PES y 463 PSO.

8 Durante el proceso electoral federal se presentaron 1350 PES y 213 PSO.

9 A lo largo del texto se dará prioridad a la presentación de los datos relacionados con los PES tramitados a nivel central. Además de las naturales limitaciones de espacio, lo anterior se justifica ya que a nivel central se resuelven los PES de las materias más relevantes en el debate público - como el nuevo modelo de comunicación política o las restricciones en materia de propaganda electoral y gubernamental- amén de que la información presentada por el IFE no suele detallar, más allá de una clasificación temática, los 
tro grandes temas, que de manera conjunta concentran el $80 \%$ de los PES: actos anticipados de precampaña o campaña (20.8\%); otro tipo de violaciones en materia de propaganda (20.4\%); adquisición o contratación de tiempo en radio o televisión (19.9\%), y propaganda que denigra a las instituciones o calumnia a las personas (18.1\%). Las categorías restantes se presentan con una frecuencia mucho menor: $11.3 \%$ de los PES estuvieron relacionados con la difusión de propaganda gubernamental en tiempos prohibidos; $8.1 \%$ con violaciones al artículo 134 constitucional - ya sea por promoción personalizada de servidores públicos o por la no aplicación imparcial de recursos-; 1.1\% con el incumplimiento de medidas cautelares dictadas por la Comisión de Quejas y Denuncias del IFE; y $0.2 \%$ con el incumplimiento en la transmisión de la pauta ordenada por la autoridad administrativa electoral.

\section{Gráfica II \\ Clasificación de PES a nivel central por tipo de infracción}

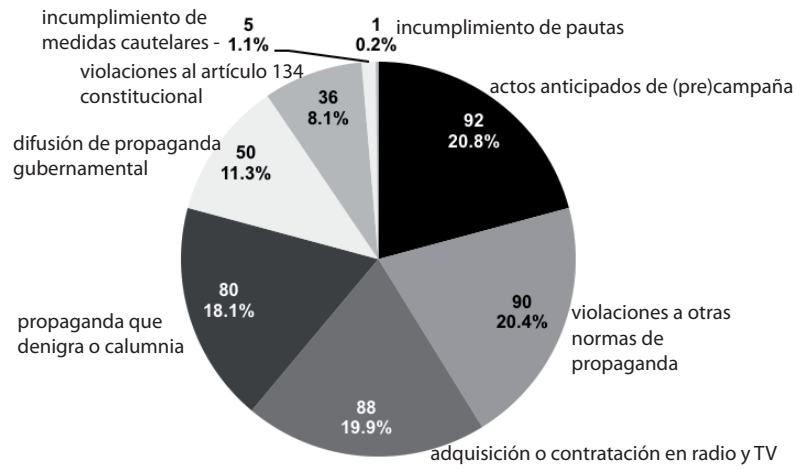

Fuente: elaboración propia con base en datos del IFE.

datos de los procedimientos a nivel distrital. De acuerdo con la referida clasificación, los PES a nivel distrital se distribuyeron de la siguiente forma: 617 casos (68.0\% del total) estuvieron relacionados con violaciones a la normatividad en propaganda diferente a la difundida en radio y televisión; $136(15.0 \%)$ con la difusión de propaganda gubernamental; 118 (13.0\%) con actos anticipados de precampaña o campaña, y 37 (4.1\%) con violaciones al artículo 134 constitucional. De estas cifras, destaca que a nivel distrital el porcentaje de PES relacionados con actos anticipados de precampaña y campaña representa casi la mitad del que se tiene para el ámbito central (13.0\% contra $20.8 \%)$. De hecho, a nivel distrital sólo se presentaron 26 quejas más relacionadas con este tópico, no obstante que la comparación de universos indica, como se apuntó, una diferencia de más del doble. Lo anterior sugiere que es menos atractivo, en términos mediáticos, denunciar actos anticipados en los consejos distritales del IFE, lejos de los reflectores. 
Los anteriores datos muestran, primeramente, que el mayor número de quejas y denuncias estuvo relacionado con temas potencialmente atractivos en términos mediáticos. En efecto, durante los últimos años, es común ver que los partidos denuncien —con poco o nulo sustento jurídico- a candidatos o funcionarios pertenecientes a otros institutos políticos por la presunta promoción de su imagen fuera los tiempos que marca la ley, por la adquisición de tiempo en radio y televisión -mediante entrevistas simuladas o infomerciales, por ejemplo- o por la difusión de propaganda calumniosa o denigrante. En contraste, la evidencia muestra que son relativamente escasos los PES iniciados por violaciones de carácter técnico, como el incumplimiento de pautas.

Otra variable por demás relevante es la forma en que, a nivel central, el IFE resolvió los PES del proceso electoral federal 2011-2012. En ese sentido, los datos de la gráfica III son elocuentes. Destaca que sólo el $20.6 \%$ de los procedimientos fueron declarados fundados o parcialmente fundados, esto es, sólo en uno de cada cinco PES se demostró la existencia de una violación a la normativa electoral. En cambio, la inmensa mayoría de los PES se declararon infundados (60.9\%) y otro tanto más se desechó (11.4\%). ${ }^{10}$ Dicho de otra manera, la mayoría de las quejas y denuncias carecieron de un sustento sólido, circunstancia que abona el discurso de quienes denuncian la utilización del PES, por parte de los partidos políticos, no tanto como una vía para asegurar la regularidad del proceso electoral, sino como un medio más de propaganda. ${ }^{11}$

10 En la categoría de "otro sentido" se agrupan las resoluciones por las que se determinó remitir las quejas a juntas distritales (12 casos), los acuerdos de incompetencia (7) y las bajas administrativas (6).

11 Cabe enfatizar que los partidos políticos presentaron el grueso de las quejas y denuncias de los PES tramitados a nivel central. De acuerdo con datos del propio IFE, el 96.6\% de los PES (427 de 442) fueron iniciados a instancia de parte. En 296 casos (7 de cada 10) el denunciante fue un partido político. 


\section{Gráfica III \\ Sentido de la resolución de los PES a nivel central}

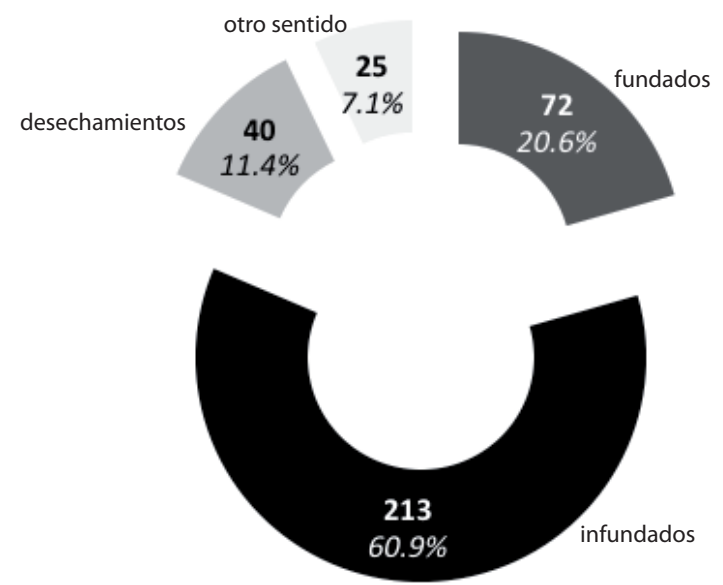

Fuente: elaboración propia con base en datos del IFE.

En cuanto a los tiempos de resolución de los procedimientos sancionadores, de acuerdo con la información proporcionada por el propio IFE, las quejas y denuncias de los PES se resolvieron en un promedio de 45 días. Como puede verse, el dato es poco alentador, sobre todo si se considera que, conforme los tiempos establecidos en el Cofipe, los PES deben resolverse entre 5 y 6 días. ${ }^{12}$ De hecho, en la práctica el tiempo promedio de resolución de los PES se encuentra mucho más cerca de los tiempos que el legislador secundario ideó para los PSO (64 días aproximadamente).

No sorprende, por tanto, que la prolongación de los tiempos de resolución se traduzca en un rezago nada despreciable. El IFE reportaba que el 23 de agosto de 2012 - esto es, una semana antes de que concluyera el proceso electoral federal 2011-2012- más de una quinta parte (el 20.8\%) de las quejas y denuncias de PES seguían sin resolverse. ${ }^{13} \mathrm{Y}$

12 En la sentencia correspondiente al recurso de apelación SUP-RAP-58/2008 puede consultarse una tabla comparativa entre los tiempos de resolución de los procedimientos ordinario y sancionador.

${ }_{13}$ Este porcentaje podría explicarse por el hecho de que una gran cantidad de quejas y denuncias son presentadas durante los últimos meses del proceso electoral federal. Empero, los datos muestran que el rezago se mantuvo incluso cuando el proceso había finalizado. Por ejemplo, para el 10 de octubre - 40 días después de que había finalizado el proceso electoral- el porcentaje de quejas y denuncias sin resolver era de $17.3 \%$. Lo 
aunque resulta razonable que el IFE haya priorizado la resolución de cierto tipo de asuntos, como los relativos a los actos anticipados o a la propaganda denigrante o calumniosa, ello supuso que se demorara aún más la resolución de otras materias relevantes, como la difusión de propaganda gubernamental o la adquisición de tiempo en radio y televisión. $^{14}$

En otro orden de ideas, conviene analizar cuáles fueron las principales tendencias en la presentación y resolución de medidas cautelares, una figura especialmente relevante, pues es la que permite al IFE ordenar, de manera pronta, el retiro de propaganda que, prima facie, viole alguna norma electoral. ${ }^{15}$ En este sentido, destaca que se hayan presentado 208 solicitudes de medidas cautelares en PES. Esto significa, grosso modo, que por cada dos quejas o denuncias de PES a nivel central se presentó una solicitud de medidas cautelares. ${ }^{16}$

Las solicitudes de medidas cautelares se resolvieron de la siguiente forma: ${ }^{17}$ en el $17.6 \%$ de los casos se desecharon las solicitudes, en el $65.2 \%$ se negaron las medidas cautelares y sólo en el $16.7 \%$ las medidas fueron procedentes. ${ }^{18}$ Que sólo un reducido porcentaje de solici-

anterior evidencia que, en realidad, el rezago se explica por el elevado número de días que el IFE puede tardar en el resolver los PES y no por la fecha de su presentación.

14 De acuerdo con el IFE, para el 23 de agosto de 2012 se había resuelto el $97.8 \%$ de los asuntos relacionados con actos anticipados de precampaña o campaña y el $85.0 \%$ de los relativos a la difusión de propaganda presuntamente calumniosa o denigrante. En cambio, sólo se había resuelto el $66.0 \%$ de las quejas relacionadas con la difusión de propaganda gubernamental y con el $60.2 \%$ de las relativas a la contratación o adquisición de tiempo en radio o televisión.

${ }^{15}$ El IFE presenta la siguiente distribución temática sobre las solicitudes de medidas cautelares: propaganda contraria a la normatividad electoral, $22.7 \%$ (56 solicitudes); propaganda que presuntamente denigra o calumnia, 21.1\% (52); violaciones al artículo 134 constitucional, $16.6 \%$ (41); propaganda gubernamental, 13.7\% (33); actos anticipados de precampaña o campaña $13.0 \%$ (32); contratación o adquisición de tiempo en radio y/o televisión, 9.7\% (24), y coacción al voto 3.6\% (9). Sin embargo, esta clasificación debe tomarse con reserva, pues sólo se presentan datos agregados, que no distinguen entre procedimientos ordinarios y sancionadores.

${ }^{16}$ Ello pues se presentaron 442 quejas o denuncias de PES a nivel central y 208 solicitudes de medidas cautelares, lo cual da una tasa de 2.13 PES/cautelares.

17 Aquí vale la advertencia de la nota anterior, pues la información del IFE no distingue entre PES y PSO, aunque cabe suponer que las cifras están referidas en su gran mayoría a los PES, no sólo por ser la vía que con más frecuencia se presenta, sino porque en los hechos son extremadamente atípicos los casos en los cuales se solicitan medidas cautelares en un PSO.

18 En el caso restante (0.4\%) se dictó un acuerdo de incompetencia. 
tudes de medidas cautelares haya sido fundado refuerza la idea de que éstas también suelen ser utilizadas con fines de impacto mediático.

\section{Sede judicial: los RAP interpuestos contra PES ${ }^{19}$}

Vistas las principales tendencias que se presentaron en la sede administrativa, conviene analizar los RAP que se interpusieron contra los PES relacionados con el proceso electoral federal 2011-2012. La gráfica IV muestra un primer dato destacable: dos de cada tres RAP (403 de un total de 604) se interpusieron contra determinaciones vinculadas con la tramitación o resolución de PES, mientras que sólo el $1.3 \%$ estuvo relacionado con PSO, 13.2\% con la integración de órganos del IFE, $3.5 \%$ con los procedimientos de fiscalización y $15.2 \%$ con otro tipo de resoluciones. Como puede verse, la "excepcionalidad" de los PES también es inexistente en la sede judicial, aunque en este caso la disparidad es todavía mayor.

\section{Gráfica IV}

\section{Temas de los RAP relacionados con el proceso federal electoral}

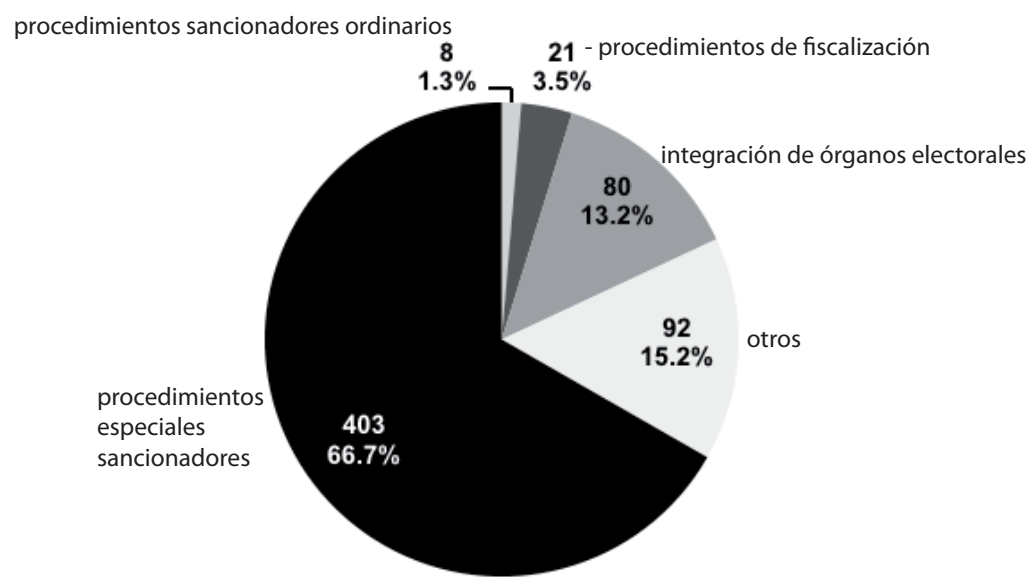

Fuente: elaboración propia con base en datos del TEPJF.

19 Los datos que se presentan en este apartado fueron elaborados con base en la información proporcionada por la Dirección General de Estadística e Información Jurisdiccional del TEPJF. 
Un segundo dato relevante consiste en comparar cuántos RAP se interpusieron contra PES tramitados a nivel central y cuántos a nivel distrital. A diferencia de lo que sucede en la sede administrativa -en donde los distritales predominan sobre los centrales en una proporción de dos a uno- aquí se advierte una tendencia opuesta: el $54.8 \%$ de los RAP fueron interpuestos contra procedimientos centrales, mientras que $45.2 \%$ contra distritales. ¿Cómo explicar lo anterior? Por una parte, podría pensarse que en los PES a nivel central se debaten temas de mayor relevancia y, por ende, se tienen más incentivos para impugnar. Más aún, esta relevancia también favorece el uso propagandístico de los procedimientos sancionadores: resulta mucho más redituable, en términos mediáticos, presentar una denuncia ante el Consejo General del IFE (CGIFE) - el cual suele contar con amplia cobertura periodística- que ante un consejo distrital -en el que probablemente no habrá medios de comunicación-. Sin embargo, también debe considerarse que, en el caso de los PES a nivel distrital, existe una instancia administrativa anterior a la apelación, el recurso de revisión, cuyo conocimiento y resolución corresponde a los consejos locales del IFE.

Ahora bien, ¿qué tipos de asuntos se abordan en los RAP interpuestos contra procedimientos centrales? ${ }^{20}$ En este rubro también se pueden advertir diferencias notables respecto de la sede administrativa. Si en esta última había un claro predominio de cuatro temas - cada uno con un $20 \%$ del total-, en la sede judicial el mayor número de asuntos estuvo relacionado con actos anticipados de precampaña o campaña (36.7\%), seguido lejanamente por la propaganda calumniosa o denigrante $(12.7 \%)$, las medidas cautelares $(12.2 \%)$, la difusión de propaganda gubernamental (10.9\%), las violaciones al artículo 134 constitucional (9.5\%) y las infracciones a otras normas de propaganda (8.6\%).

Por una parte, es notable que dos de los temas que se presentaron con menor frecuencia - contratación o adquisición de tiempo en radio y TV (6.8\%) y el incumplimiento de pautas $(2.3 \%)$ - tengan

${ }^{20}$ La distribución temática de los RAP interpuestos contra PES a nivel distrital fue la siguiente. Se presentaron 117 (64.3\%) impugnaciones por colocación de propaganda en lugares prohibidos; 23 (12.6\%) por actos anticipados de campaña o precampaña; $20(11.0 \%)$ por la difusión de propaganda gubernamental durante campañas y hasta la conclusión de jornadas electorales; 10 (5.5\%) contra la omisión de retirar propaganda; 7 (3.8\%) por propaganda que incumple con algún otro requisito legal; 3 (1.6\%) por violaciones al artículo 134 constitucional, y 2 (1.1\%) por otros motivos. 
un fuerte componente técnico. Parecería, por tanto, que en este renglón existe, en términos generales, un adecuado funcionamiento del denominado "nuevo modelo de comunicación política". Por la otra, también destaca que las medidas cautelares tengan una baja tasa de impugnabilidad. Como se había referido, en el proceso electoral se realizaron 208 solicitudes de medidas cautelares, pero sólo se presentaron 27 impugnaciones.

\section{Gráfica V}

Temas de los RAP relacionados con el proceso federal electoral

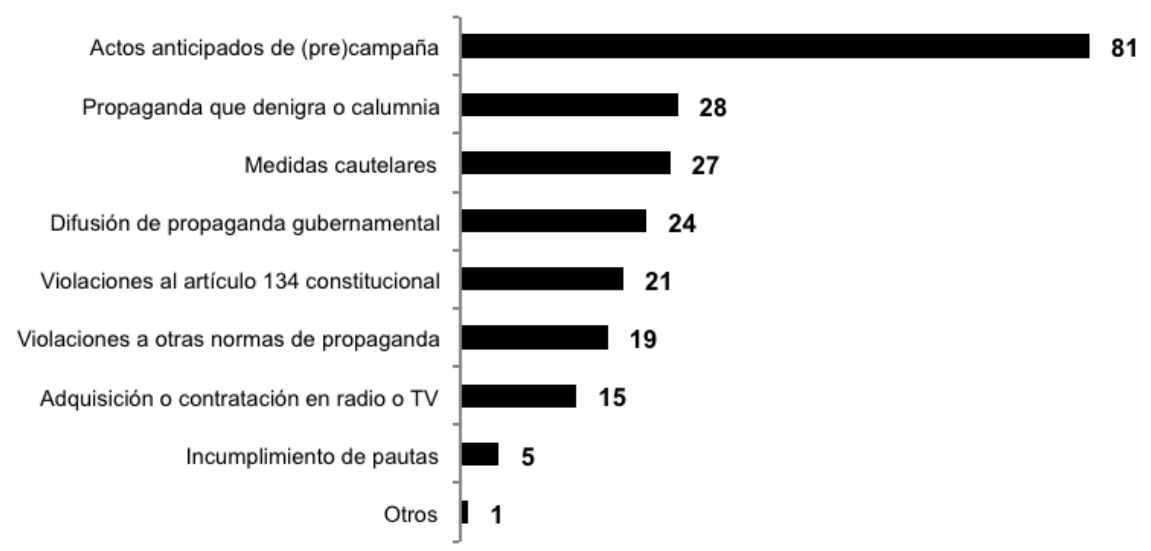

Fuente: elaboración propia con base en datos del TEPJF.

Veamos, ahora, la forma en que se resolvieron los RAP interpuestos contra PES a nivel central. Lo primero a destacar es que sólo el $35.4 \%$ de los casos (75) la SSTEPJF determinó que los agravios hechos valer por los recurrentes eran, en todo o en parte, fundados. En cambio, en el $49.5 \%$ (105) los agravios fueron considerados como infundados; en el 7.1\% (15) se actualizó alguna causal que impidió el dictado de una sentencia de fondo, y en el $8.0 \%$ restante (17) el asunto se resolvió con el dictado de algún tipo de acuerdo. ${ }^{21}$ Lo anterior significa que en una

${ }^{21}$ A la fecha de corte de la información proporcionada por la Dirección General de Estadística e Información Jurisdiccional del TEPJF (10 de octubre de 2012), 9 asuntos se encontraban pendientes de resolución. 
de cada tres impugnaciones la SSTEPJF modificó o revocó la determinación adoptada inicialmente por el IFE.

La gráfica VI permite ver, entre otras cosas, cómo se encuentra distribuido temáticamente el conjunto de sentencias de RAP que modificaron o revocaron el acto o resolución impugnado. Por mucho, los procedimientos en los que se revocó más fueron los relativos a violaciones al artículo 134 de la CPEUM: en 7 de cada 10 casos se estimaron fundados o parcialmente fundados los agravios de los recurrentes. También se encuentran por encima del promedio (35.4\%) los RAP relacionados con propaganda que presuntamente denigra o calumnia (42.9\%) y los relativos a la difusión de propaganda gubernamental (41.7\%). En cambio, tienen el menor porcentaje de éxito los RAP que guardan relación con la contratación o adquisición en radio o televisión (22.2\%), así como en los que se plantea el incumplimiento de pautas $(20.0 \%)$.

¿Qué nos dicen estos datos? Por una parte, el elevado porcentaje de revocaciones de RAP relacionados con violaciones al artículo 134 de la Constitución da cuenta de las complicaciones que supone operar dicho precepto sin una ley reglamentaria. Sin parámetros claros, es fácil que existan discrepancias en los criterios, empezando por el papel de las autoridades electorales en un mandato constitucional que trasciende lo electoral para comprender toda actividad de los órganos estatales. ${ }^{22}$ Por otra parte, que se confirme la inmensa mayoría de los PES relacionados con el cumplimiento de pautas y con la contratación o adquisición de tiempo en radio y TV refuerza la hipótesis de que, en el aspecto más técnico, el nuevo modelo de comunicación ha funcionado bien. Por último, llama la atención que los actos anticipados de precampaña o campaña hayan motivado el mayor número de RAP — casi dos quintas partes del total-, pero que, una vez analizados en el fondo, sólo uno de cada cuatro sean fundados. De nuevo, parecería que estos datos revelan el uso estratégico que los partidos políticos dan a la presentación de quejas y denuncias contra sus adversarios.

22 Véase, en este sentido, la posición de la Suprema Corte de Justicia de la Nación sobre los alcances del artículo 134 de la CPEUM, en la parte que interesa: sentencias a las acciones de inconstitucionalidad 33/2009 y sus acumuladas 34/2009 y 35/2009, así como en la $55 / 2009$. 


\section{Gráfica VI \\ Sentido de la resolución de los RAP (por tema)}

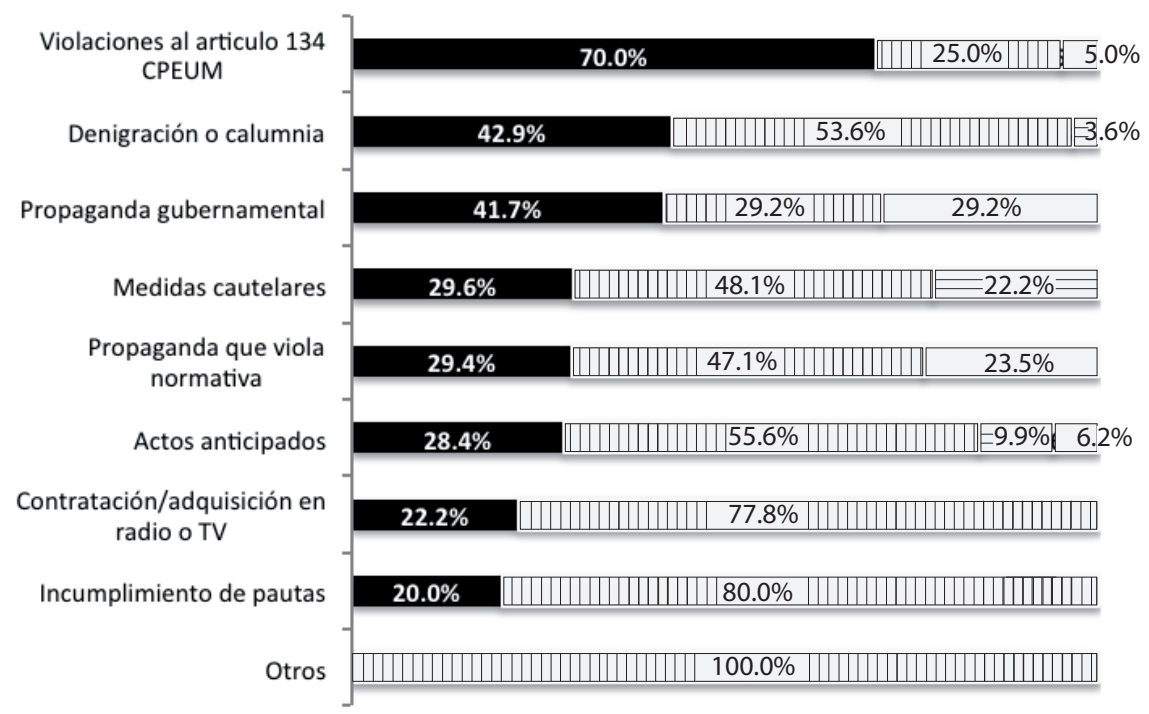

\section{- Fundado $\square$ Infundado $\quad$ IImprocedencia $\quad \square$ Acuerdo}

Fuente: elaboración propia con base en datos del TEPJF.

Finalmente, conviene analizar cuáles fueron los tiempos de resolución de los RAP relacionados con PES a nivel central. La SSTEPJF resolvió los recursos en un promedio de 24.5 días, casi la mitad del tiempo que el IFE tarda en resolver las quejas y denuncias de PES, pero que igualmente evidencia las complicaciones que, en la práctica, supone la resolución definitiva de los procedimientos especiales.

Más aún, la gráfica VII muestra que el tiempo promedio de resolución es alto para prácticamente todos los tipos de controversia. Cercanos al promedio se encuentran la contratación o adquisición de tiempo en radio o televisión (20.4 días), la propaganda denigrante o calumniosa (21.1), otras violaciones en materia de propaganda (25.1) y la difusión de propaganda gubernamental (26.5). Los asuntos que más tardan en resolverse son los relacionados con violaciones al artículo 134 constitucional (30.9) y los relativos a actos anticipados de campaña y precampaña (31.7). En cambio, las apelaciones que se resuelven con mayor rapidez son las relacionadas con el incumpli- 
miento de pautas (13 días) y, especialmente, las relativas a medidas cautelares (4.4).

\section{Gráfica VII}

Sentido de la resolución de los RAP (por tema)

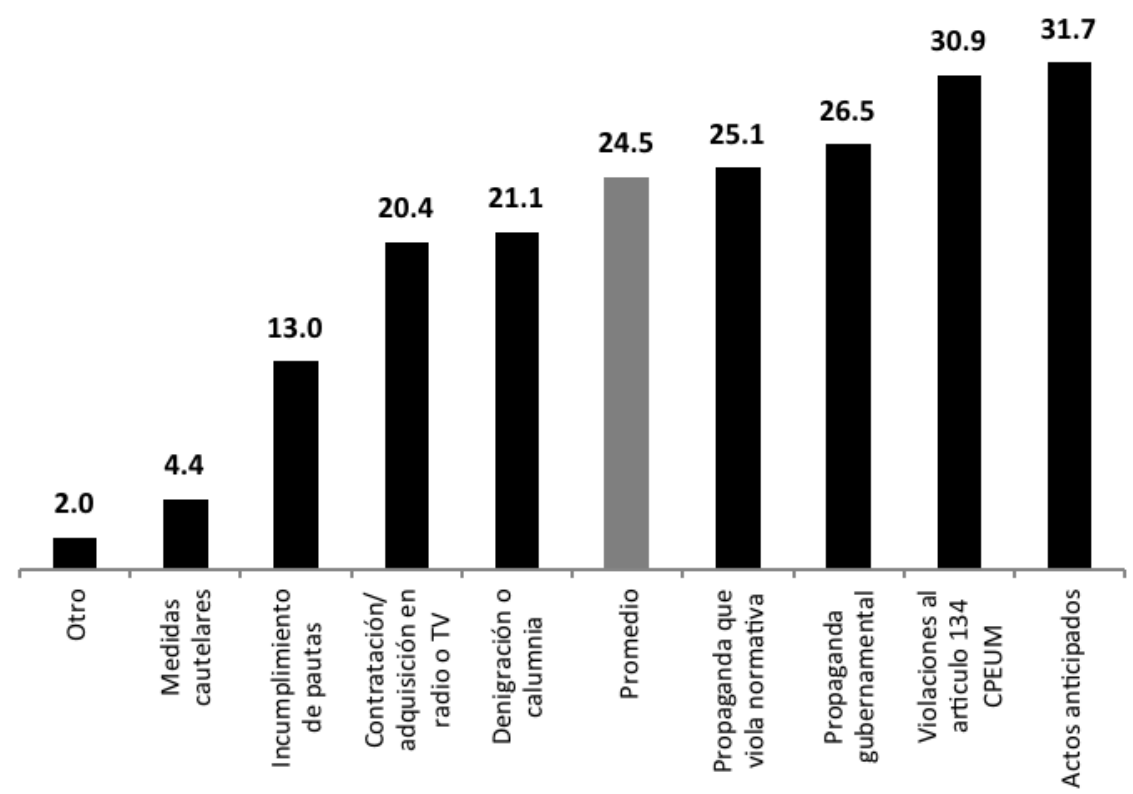

Fuente: elaboración propia con base en datos del TEPJF.

Conviene resaltar tres cosas. En primer lugar, resulta destacable que el mayor número de RAP se presente contra PES relacionados con actos anticipados de campaña, pero que, al mismo tiempo, sean las controversias que, en promedio, más tiempo requieren para ser resueltas en la sede jurisdiccional. En segundo lugar, estos datos, de nueva cuenta, permiten ver las dificultades que supone, para la interpretación y aplicación del artículo 134 constitucional, la falta de una ley reglamentaria. La ausencia de parámetros claros no sólo se traduce en un mayor número de revocaciones por parte de la SSTEPJF, sino también, al parecer, en mayores tiempos para la resolución de estas controversias. En tercer lugar, la nota más positiva es que los RAP relacionados con medidas cautelares se resuelven en breve término. 


\section{Conclusiones y propuestas de reforma}

¿Cuáles son las principales lecciones que nos deja el proceso electoral federal 2011-2012? Una ponderación general de los primeros años de su implementación, permite afirmar que el PES se ha vuelto, por emplear una expresión popular, "ajonjolí de todos los moles", dado que por la vía de la reforma constitucional o legal, o por la interpretación judicial de sus normas reguladoras, se ha aumentado de manera progresiva el tipo de asuntos que se ventilan a través del mismo. Esta situación que ha contribuido a que no se haya aún perfilado nítidamente en la función que está llamado a cumplir el PES, por lo que continuamente se cuestiona su utilidad o, en otros casos, si debiera corresponder su conocimiento a la autoridad judicial.

A partir de las cifras analizadas consideramos que la evidencia empírica que se ha presentado muestra que el diseño actual del PES presenta tres grandes problemas. En primer lugar, existe una tensión entre: a) la resolución de los PES en los - brevísimos- plazos que marca la ley, y $b$ ) allegarse de todos los elementos necesarios para la imposición de sanciones. Dicho de otra manera, el IFE ha encontrado dificultades para desahogar los PES a tiempo - y el TEPJF para resolver las respectivas impugnaciones - por la concurrencia de las vertientes reparadora y sancionadora en un mismo procedimiento.

En segundo lugar, los datos muestran con claridad que el catálogo de infracciones que pueden conocerse mediante el PES ha crecido a tal grado que, en la actualidad, dicho procedimiento ha perdido su carácter "excepcional" o "especial".

En tercero, a partir de cómo viene funcionando en la actualidad el PES, la evidencia presentada sugiere que el CGIFE no es el órgano más adecuado para la sustanciación y resolución del PES. ${ }^{23}$ La presencia

${ }^{23}$ Por el contrario, si el PES se perfilara como instrumento a cargo de la autoridad administrativa electoral que le permitiera, como complemento de su facultad de emitir acuerdos generales y demás lineamientos relacionados con su órbita competencial, ir definiendo la manera en la que deben interpretarse y aplicarse disposiciones sustantivas del ejercicio de los derechos políticos en el marco de un proceso electoral, podría arribarse a una conclusión diversa. De replantearse así, además de circunscribirse con precisión los aspectos que podrían analizarse en estos asuntos, cambiaría incluso el enfoque a partir del cual la SSTEPJF debiera analizar las impugnaciones relacionadas con acuerdos y resoluciones dictados en el desahogo de los PES. 
permanente de los partidos políticos — quienes pueden intervenir con voz en sus sesiones-, así como la gran atención mediática que recibe, crean incentivos perversos, que favorecen la presentación de denuncias con fines predominantemente políticos.

En razón de lo anterior, a continuación se delinean tres propuestas concretas que permitirían mejorar el funcionamiento del PES. ${ }^{24}$

\section{Diferenciación de las funciones reparadora y sancionadora del PES}

En la práctica, la resolución en sede administrativa de los PES demora 45 días en promedio, lo cual rebasa con creces los tiempos establecidos en la ley. ${ }^{25}$ Asimismo, un mes después de finalizado el proceso electoral, una de cada seis quejas o denuncias de PES seguía sin resolverse, de tal suerte que, al menos en estos casos, el procedimiento incumplió con su finalidad reparadora. Ello se debe, en buena medida, a que el diseño actual del PES obliga a que en el mismo procedimiento se repare la infracción a la ley y, a la par, se imponga una sanción cuando se acredite la existencia de la violación y la responsabilidad de algún sujeto. Esta fórmula normalmente entorpece el dictado expedito de una resolución reparadora - que eventualmente puede frustrarse si no fueron concedidas en su oportunidad las medidas cautelares- pues incluso es necesario allegarse de elementos de convicción indispensables para la individualización de la sanción, como son los relacionados con la capacidad económica del infractor, que no están a disposición de la autoridad administrativa en la generalidad de los casos, o bien, que pueden motivar diferencias interpretativas entre ésta y la autoridad jurisdiccional. ${ }^{26}$

${ }^{24}$ Los rasgos generales de dichas propuestas habían sido presentados con anterioridad en Zavala Arredondo, Marco Antonio, op. cit., pp. 409-416.

${ }^{25}$ La demora en la resolución de procedimientos especiales parece no ser exclusiva del ámbito federal. De acuerdo con González, “[e]n el ámbito local se han presentado casos en que la autoridad administrativa electoral ha retardado la resolución de los procedimientos administrativos sancionadores por conductas acaecidas durante el desarrollo del proceso electoral por más de 16 meses". González García, María de Jesús, "Inconsistencias del procedimiento administrativo sancionador electoral", México, FEPADE Difunde, núm. 17, 2009, p. 113.

26 González señala que uno de los “[e]jemplos claros de la falta de consenso respecto de los enunciados normativos que regulan el procedimiento administrativo, tanto a nivel 
Lo más conveniente, en nuestro concepto, sería limitar el PES a la función reparadora del modelo inicial ${ }^{27}$ y que el procedimiento sancionador se tramite por separado, ${ }^{28}$ conforme a las reglas del ordinario, salvo que la eventual infracción pueda tener repercusión en el desarrollo del proceso y, específicamente, en la esfera del sujeto infractor que participa o pretende participar en los comicios - actos anticipados de precampaña y de campaña, por ejemplo-, en cuyo caso debería resolverse antes de la finalización del momento correspondiente del proceso electoral.

\section{Acotar el catálogo de infracciones que se resuelven vía PES}

\section{La experiencia del proceso electoral federal ha mostrado que el catálo- go de materias que se resuelven a través del PES es demasiado extenso.}

federal como local" es "la calificación e individualización de la sanción". Ibidem, p. 94. En sentido similar, Jaime del Río señala que es necesario "zanjar los problemas que presentan la determinación e individualización de sanciones y, eventualmente, poner reglas suficientes, claras y uniformes en esta materia". Cfr. Río Salcedo, Jaime del, "Determinación e individualización de sanciones en el nuevo régimen administrativo sancionador electoral", FEPADE Difunde, núm. 17, 2009, p. 67.

27 Cfr. la jurisprudencia 2/2008, con el rubro Procedimiento especializado de urgente resolución. Naturaleza y finalidad, Gaceta de Jurisprudencia y Tesis en materia electoral, TEPJF, año 1, núm. 2, 2008, pp. 43 y 44. En dicha jurisprudencia establecen los rasgos fundamentales de la configuración original de dicha figura: "El procedimiento especializado... es de naturaleza preponderantemente preventivo y de carácter provisional; su finalidad esencial consiste en evitar que la conducta presumiblemente trasgresora de la normativa electoral, como podría ser la difusión de actos anticipados de precampaña o campaña, de propaganda negra o denostativa, entre otros, genere los efectos perniciosos e irreparables, ello a través de medidas tendentes a lograr la paralización, suspensión o cesación de los actos irregulares; a diferencia de lo que sucede con el procedimiento sancionador, cuya naturaleza es eminentemente coercitiva y ejemplar de los modelos de conducta; su objetivo fundamental consiste en la investigación de actos o conductas infractoras de la normativa electoral que puedan afectar el proceso electoral, a fin de aplicar la sanción correspondiente".

28 De hecho, el derecho comparado muestra que por lo general el ejercicio de las potestades disciplinaria y sancionadora de la administración electoral se controla por canales o vías ordinarias, normalmente diversas de las existentes para aquellos actos "incardinados en el proceso electoral", sujetos a un régimen específico, por lo apretado de los plazos y las características de las elecciones. Para el caso de España, $c f r$. Fuentes Badarjí, Joaquín de, et. al., Manual de Derecho administrativo sancionador, Cizur Menor, Ministerio de Justicia-Thomson Arizandi, 2005, pp. 1405-1413, y Pascua Mateo, Fabio, El control de las elecciones, Cizur Menor, Civitas-Thomson Reuters, 2009, pp. 25 y 26. 
El procedimiento especial se ha vuelto la regla; mientras que el ordinario, la excepción. En la sede administrativa, por cada procedimiento ordinario se interpusieron 6 especiales; mientras que el $66.7 \%$ de los RAP vinculados con el proceso electoral federal se interpusieron contra resoluciones dictadas en PES. Más aún, se estimó como fundados un porcentaje claramente minoritario de las quejas y denuncias de PES (20.6\%), de las solicitudes de medidas cautelares (16.7\%) y de los recursos de apelación (35.4\%).

En consecuencia, convendría analizar cuáles son las materias que efectivamente ameritan ser resueltas mediante el PES, y cuáles otras podrían ser resueltas mediante los PSO, o bien, fuera de la jurisdicción electoral. Por ejemplo, las controversias relacionadas con la propaganda que presuntamente calumnia a las personas bien podrían resolverse por la vía civil, ante una autoridad jurisdiccional. Sobre todo, porque la previsión legal vigente - que incorpora el principio de rogación para la instauración de los PES en esta materia- es francamente incompatible con el andamiaje constitucional y legal, ${ }^{29}$ así como con la naturaleza preponderantemente inquisitiva que, por lo común, caracteriza a los procedimientos sancionadores administrativos.

\section{Redefinir los órganos competentes para el conocimiento del PES}

Por su diseño, el CGIFE no es el órgano más adecuado para la resolución de los procedimientos sancionadores, en general, y de los PES, en particular. Su numerosa conformación - ocho consejeros electorales, un presidente, un representante por cada uno de los partidos políticos con registro y otro por cada grupo parlamentario, así como el secretario ejecutivo- dificulta que pueda reunirse rápida y reiteradamente, al compás de las denuncias presentadas por los actores políticos. Además, el natural foco de interés que representa para la opinión pública todo lo que se hace y se dice al seno del CGIFE ha provocado una especie de "caja de resonancia" de lo que en las sesiones se debate, circunstancia que a su vez ha incidido en que la presentación de de-

${ }^{29}$ En especial, con las atribuciones de vigilancia y supervisión conferidas al IFE en los artículos 109 y 118.1 , incisos $h$ y $t$, del Cofipe. 
nuncias se transforme en una herramienta de campaña durante las elecciones. ${ }^{30}$

El CGIFE, pues, no está diseñado para adoptar resoluciones cotidianas - para eso se cuenta con la rama ejecutiva del IFE, que precisamente instrumenta y opera a partir de las directrices del máximo órgano de dirección-, sino decidir las cuestiones más importantes en la materia, aquellas que van dando sentido y rumbo a la función electoral. Pero lo anterior se complica cuando el CGIFE se ve obligado a discutir y resolver los procedimientos sancionadores en una mesa donde tienen presencia y voz los posibles infractores.

Una alternativa, que incluso no precisaría de una modificación constitucional, consistiría en conceptualizar la resolución de los PES como una actividad con marcado acento técnico, encargada a un cuerpo de especialistas en las materias susceptibles de ser desahogadas en los mismos, más que una arena para el discurso político. En la medida en que se perfile una solución en este sentido, se focalizaría el tratamiento de las denuncias desde una óptica jurídica y se establecerían condiciones para eliminar los incentivos perversos que hasta el momento se han generado con la intervención de primera mano del CGIFE o de una comisión de sus integrantes. No sugerimos, por supuesto, que la instancia profesional que aludimos se mantenga ajena a la órbita directiva del CGIFE, pero sí sería necesaria la autonomía técnica en su funcionamiento, como ciertamente ya sucede con la Unidad de Fiscalización de los Recursos de los Partidos Políticos, que bien podría servir de guía o ejemplo para los propósitos que planteamos.

\section{Bibliografía}

Alanís Figueroa, María del Carmen, "La jurisprudencia del TEPJF: Fuente formal de la Reforma Electoral 2007-2008”, en Córdova Vianello, Lorenzo y Salazar Ugarte, Pedro (coords.), Estudios

30 Dado el potencial uso mediático de los PES, no sorprende que sólo 15 procedimientos especiales (el 3.4\% del total) hayan sido iniciados de oficio y que en el $69.3 \%$ de los iniciados petición de parte el denunciante sea un partido político. Como tampoco llama la atención que sólo uno de cada cinco PES se haya estimado fundado. 
sobre la reforma electoral 2007. Hacia un nuevo modelo, México, TEPJF, 2008.

AlCocer, Jorge, "Sin ton ni son", Reforma, 10 de agosto de 2010.

Aljovín Navarro, Jorge David, Procedimiento especial sancionador: manual en materia electoral, México, Porrúa, 2012.

Ballados Villagómez, Patricio, "La visión desde el Tribunal", Voz y Voto, núm. 219, mayo de 2011.

BECERRA, Ricardo, "Una reforma electoral con precisión (y sin lágrimas)", El Universal, 20 de noviembre de 2009.

_-_, "La visión desde el IFE", Voz y Voto, núm. 219, mayo de 2011.

_- - "Piensen en cargar un elefante (y luego en el IFE)", Nexos, junio de 2011, http://www.nexos.com. $m x /$ ?P=leerarticulo\&Artic $l e=2099321$.

Chacón Rojas, Oswaldo, Dinero del crimen organizado y fiscalización electoral, México, Fontamara-Comisión de Fiscalización Electoral, 2011.

Córdova Vianello, Lorenzo, “¿Árbitro electoral o MP?”, El Universal, 22 de abril de 2009.

_-_, "La reforma electoral de 2007-2008 cuatro años después: apuntes para un balance de su instrumentación", Revista Mexicana de Derecho Electoral, núm. 1, enero-junio de 2012.

Elizondo Gasperín, Ma. Macarita, Prontuario electoral. Procedimiento administrativo sancionador, México, Porrúa-UNAM, 2009.

Fuentes BADARJí, Joaquín de et. al., Manual de derecho administrativo sancionador, Cizur Menor, Ministerio de Justicia-Thomson Arizandi, 2005.

González García, María de Jesús, "Inconsistencias del procedimiento administrativo sancionador electoral", FEPADE Difunde, núm. 17, 2009.

IFE, Informe general sobre la implementación de la reforma electoral durante el proceso 2008-2009, México, IFE, 2010.

- - - "Informe que presenta el Secretario del Consejo General en cumplimiento al artículo 10 del Reglamento de Quejas y Denuncias del Instituto Federal Electoral", 23 de agosto de 2012, http://www. ife.org. $m x /$ docs/IFE-v2/DS/DS-InformesLegal/DS-ReglamentoMateria-QuejasDenuncias/docs-informes/2012/Inf_30ago12o_pto5.pdf.

Jurisprudencia 2/2008, "Procedimiento ESPECIALIZAdo DE URGENTE Resolución. Naturaleza y finalidad”, Gaceta de Jurisprudencia y Tesis en materia electoral, TEPJF, año 1, núm. 2, 2008. 
Luna Ramos, José Alejandro, "Los conflictos entre partidos políticos durante las campañas electorales: Una propuesta de ampliación a la jurisdicción electoral", Revista de la Facultad de Derecho, México, t. LVII, núm. 247, enero-junio de 2007.

Orozco Henríquez, José de Jesús, "Medios y elecciones. El reto de la equidad y la libertad de expresión", en ACKerman, John M. (coord.), Elecciones 2012: en busca de equidad y legalidad, México, UNAM-Instituto Belisario Domínguez del Senado de la República, 2011.

Pascua Mateo, Fabio, El control de las elecciones, Cizur Menor, Civitas-Thomson Reuters, 2009.

Río Salcedo, Jaime del, "Determinación e individualización de sanciones en el nuevo régimen administrativo sancionador electoral", FEPADE Difunde, núm. 17, 2009.

RoldÁn Xopa, José, El procedimiento especial sancionador en materia electoral, México, IFE, 2012.

Salazar Ugarte, Pedro, "Un IFE sin poder para sancionar", El Universal, 16 de marzo de 2010.

Woldenberg, José, “El IFE como juez”, Reforma, 18 de junio de 2009. Zavala Arredondo, Marco Antonio, "El procedimiento especial sancionador: Balance de su implementación y propuestas para su perfeccionamiento", en Luna Ramos, José Alejandro (coord.), Sistema de justicia electoral mexicano, México, Porrúa, 2011. 